\title{
Clinicopathological features of small-sized peripheral squamous cell lung cancer
}

\author{
TAKAYUKI KOSAKA, KIMIHIRO SHIMIZU, SESHIRU NAKAZAWA, MISAKI IIJIMA, \\ YOICHI OHTAKI, YOKO AZUMA, KAI OBAYASHI, TOSHITERU NAGASHIMA, \\ TOSHIKI YAJIMA, AKIRA MOGI, HIROYUKI KUWANO and KEN SHIRABE \\ Department of General Surgical Science, Gunma University Graduate School of Medicine, \\ Maebashi, Gunma 371-8511, Japan
}

Received March 22, 2019; Accepted August 20, 2019

DOI: $10.3892 / \mathrm{mco} .2019 .1951$

\begin{abstract}
Recent advances in imaging technology have enhanced the detection rate of small-sized peripheral lung cancers. The present study aimed to identify the clinicopathological differences between patients with small-sized peripheral squamous cell carcinoma (SCC) and adenocarcinoma (ADC). Patients with lung cancer who underwent radical surgical resection at Gunma University Hospital between July 2007 and October 2012 were retrospectively analyzed. Patients who exhibited small-sized peripheral tumors (pathological size, $\leq 2 \mathrm{~cm}$ ) located within the outer-third of the lung field on preoperative computed tomography were enrolled in the present study. A total of 26 patients were diagnosed with SCC and 214 with ADC. The results revealed that patients with SCC exhibited higher rates of pleural invasion, vascular invasion and lymphatic invasion compared with ADC patients. Additionally, the rate of postoperative recurrence was higher in patients with SCC compared with ADC patients. Patients with ADC were subsequently into two groups: Solid ADCs (sADC) and non-solid ADCs (nsADC), which included pure ground glass nodules and part-solid ADCs. The results revealed that the incidence of pleural invasion, vascular invasion and lymphatic invasion, and the rate of postoperative recurrence in patients with SADCs were similar to those with SCC, but were also significantly higher when compared with nsADC patients. The present study concluded that patients with SCC and SADC may not be suitable candidates for sublobar resection, despite exhibiting small tumors that are located in the peripheral lung.
\end{abstract}

Correspondence to: Dr Kimihiro Shimizu, Department of General Surgical Science, Gunma University Graduate School of Medicine, 3-39-22 Showa-machi, Maebashi, Gunma 371-8511, Japan E-mail:kmshimizu@gmail.com

Key words: lung cancer, small peripheral lung cancer, squamous cell carcinoma, sublobar resection

\section{Introduction}

Recent advances in imaging technology have enhanced the detection rate of small-sized peripheral lung cancers. Prior studies that analyzed the relationship between tumor size and prognosis revealed a favorable prognosis for small-sized tumors, especially those $\leq 2 \mathrm{~cm}$ in diameter $(1,2)$. Both randomized and non-randomized studies have revealed good outcomes for patients who underwent sublobar resection of these small-sized tumors $(3,4)$.

Squamous cell carcinoma (SCC) used to be a representative histological type of centrally-located lung cancer, but recent studies have reported an increase in peripherally-located SCCs. The incidence of peripherally-located SCCs, which was $15-30 \%$ around 25 years ago $(5,6)$, increased to nearly $50 \%$ of diagnosed or resected SCC cases (7). Previous reports have revealed a difference in clinicopathological features between central-type and peripheral-type SCCs $(8,9)$. A retrospective study showed that peripheral-type SCC had lower pathological stage, less lymphatic and vessel involvement, and less lymph node metastasis, but no significant difference in overall survival compared with central-type SCC (8). However, the frequency of lymph node metastasis in peripheral-type SCC differs between reports (10-12), and current information is insufficient to define the malignant potential or prognosis of such small-sized peripheral SCCs.

Most previous studies defined peripheral tumors as tumors located in or more peripheral to the fourth branching bronchus $(12,13)$. However, this definition is difficult to use in clinical practice, and several studies of sublobar resection have thus defined peripheral tumors as tumors located within the outer third of the lung field on preoperative computed tomography $(3,4)$, which is an easier clinical definition. However, no study has reported on the use of this definition to compare the clinicopathological and prognostic features of peripheral SCC and peripheral adenocarcinoma (ADC).

We therefore investigated the malignant potential of small-sized peripheral SCC by retrospectively comparing its clinicopathological features with those of ADC in surgically resected cases, based on the definition of 'peripheral' as the outer third of the lung field on preoperative computed tomography. 


\section{Patients and methods}

Patients. We retrospectively analyzed lung cancer patients who underwent radical surgical resection at Gunma University Hospital (Maebashi, China) between July 2007 and October 2012. We included all patients with tumors located within the outer third of the lung field on preoperative computed tomography, which were $\leq 2 \mathrm{~cm}$ in pathological size. Because our study mainly focuses on pathological characteristics, we used more accurate pathological size in this study rather than clinical size like other reports $(12,14)$. Because the aim of this study is to investigate the malignant potential of tumor itself, and not the prognostic value, we included all surgical procedures; i.e., lobectomy, segmentectomy, and wedge resection. Standard procedure was lobectomy but segmentectomy was mainly applied for tumor with predominant ground glass nodule (GGN) component and wedge resection was applied for the patients with poor performance status or pulmonary function.

Medical records for each patient were reviewed for the following clinical data: Age, sex, smoking history, disease history, procedure of operation, pathological tumor size, pleural invasion, vascular invasion, lymphatic invasion, recurrence. Because our study included cases of wedge resection with no lymph node dissection, we did not include the information of pathological lymph node metastasis. We focused our analysis on the malignant potential of the primary tumor.

The present study was approved by the Institutional Review Board of Gunma University Hospital (approval no. 2017-027). Written informed consent was obtained from all patients prior to enrolment.

Statistical analysis. Associations between histological type and clinicopathological features were analyzed using $\chi^{2}$, Fisher's, or $t$-tests. A two-sided value of $\mathrm{P}<0.05$ was considered statistically significant. All analyses were performed using SPSS 25 (IBM Co., Chicago, IL, USA).

\section{Results}

Clinical characteristics. Twenty-six patients were diagnosed with SCC and 214 with ADC. The clinical characteristics of the patients are shown in Table I. Patients with SCC were significantly older than those with ADC ( 74 years vs. 65 years; $\mathrm{P}<0.01$ ), and $80 \%$ of SCC patients were male and almost all were smokers, compared with only half of ADC patients being male and smokers, respectively. There was no significant difference in the prevalence of coexisting or previously treated other cancers $(46 \%$ vs. $34 \% ; \mathrm{P}=0.19)$ or lung comorbidities ( $27 \%$ vs. $14 \%$; $\mathrm{P}=0.07$ ) between the two groups. Wedge resection was performed more frequently in SCC compared with ADC patients ( $31 \%$ vs. $13 \%$, respectively), while segmentectomy was performed more frequently in ADC compared with SCC patients ( $25 \%$ vs. $12 \%$, respectively).

Pathological characteristics. The pathological characteristics of the patients are shown in Table II. SCC tumors tended to be larger than ADC tumors, but the difference was not significant ( $1.59 \pm 0.36$ vs. $1.43 \pm 0.39 \mathrm{P}=0.05)$. The incidences of pleural invasion ( $33 \%$ vs. $13 \%$; $\mathrm{P}<0.01)$, vascular invasion ( $50 \%$ vs. $15 \%$;
$\mathrm{P}<0.01)$, and lymphatic invasion (50\% vs. 19\%; $\mathrm{P}<0.01)$ were significantly higher in the SCC compared with the ADC group.

Postoperative recurrence. The median follow-up periods were 38.5 months for SCC patients and 58.0 months for ADC patients (Table III). The rate of postoperative recurrence was higher in SCC compared with ADC patients (23\% vs. 10\%; $\mathrm{P}=0.04)$. $\mathrm{SCC}$ tended to be associated with distant metastases whereas ADC was associated with locoregional metastases, though there was no significant difference in the pattern of recurrence $(\mathrm{P}=0.08)$.

Comparison between SCC and two types of ADC. Because ADCs with GGN component are well known to be tumors with good prognosis, we divided ADCs into two groups; solid ADC (sADC) and non-solid ADC (nsADC) including pure GGN and part-solid GGN. There was no SCC with GGN feature. The incidences of pleural invasion, vascular invasion, and lymphatic invasion of SCC were similar with SADC but significantly higher compared with the nsADC group (Table IV). The rate of postoperative recurrence was similar with sADC but significantly higher compared with the nsADC group (Table V).

\section{Discussion}

In this study, we retrospectively examined the clinicopathological features of small-sized peripheral SCC in relation to its malignant potential. The incidences of pleural invasion, vascular invasion, and lymphatic invasion were all significantly higher in SCC compared with ADC, and SCC patients had a significantly higher postoperative recurrence rate when compared with ADC patients. However, there was no difference when we compared between SCC and SADC.

Previous studies have shown various results regarding the malignancy of peripheral SCC. The studies which compared peripheral and central SCC revealed that growth pattern, morphology, and immunophenotype differ between peripheral and central SCC, although there was no difference in prognosis $(8,9)$. The studies which compared SCC and ADC showed that small-sized peripheral SCC had a poorer prognosis than ADC $(15,16)$. In this study, we analyzed the malignant potential limited to peripheral small-sized tumor according to $\mathrm{CT}$ definition. We analyzed only post-operative recurrence and our results showed that SCC patients had a higher postoperative recurrence rate compared with ADC patients. Because various previous studies including ours of small-sized peripheral SCC contained small sample size, further large-scale analysis is required for further conclusion.

The present study found significantly higher incidences of pleural invasion, vascular invasion, and lymphatic invasion in patients with SCC compared with ADC. Visceral pleural invasion has been reported as a factor associated with poor prognosis, and the presence of pleural invasion increased the T stage from T1 to T2 in a recent TNM classification (17-19). Several reports suggested a possible cancer cell pathway from a tumor with pleural invasion through the pleural cavity and subpleural lymphatics and from hilar lymph nodes into the mediastinal lymph nodes $(17,20)$. Vascular invasion was 
Table I. Clinical characteristics of patients with SCC and ADC.

\begin{tabular}{|c|c|c|c|}
\hline Variables & $\operatorname{SCC}(n=26)$ & $\operatorname{ADC}(n=214)$ & P-value \\
\hline Median age, years (range) & $74(59-82)$ & $65(33-87)$ & $<0.01$ \\
\hline \multicolumn{4}{|l|}{ Sex } \\
\hline Male & $21(81 \%)$ & $108(50 \%)$ & \multirow[t]{2}{*}{$<0.01$} \\
\hline Female & $5(19 \%)$ & $106(50 \%)$ & \\
\hline \multicolumn{4}{|l|}{ Smoking history } \\
\hline Never & $1(4 \%)$ & $99(46 \%)$ & \multirow[t]{2}{*}{$<0.01$} \\
\hline Current or former & $25(96 \%)$ & $114(54 \%)$ & \\
\hline \multicolumn{4}{|l|}{ Lung comorbidity } \\
\hline Absent & $19(73 \%)$ & $185(86 \%)$ & \multirow[t]{5}{*}{0.07} \\
\hline Present & $7(27 \%)$ & $29(14 \%)$ & \\
\hline COPD & 3 & 25 & \\
\hline IP & 3 & 3 & \\
\hline CPFE & 1 & 1 & \\
\hline \multicolumn{4}{|c|}{ Coexisting or previously treated other cancer } \\
\hline Absent & $14(54 \%)$ & $142(66 \%)$ & \multirow[t]{2}{*}{0.19} \\
\hline Present & $12(46 \%)$ & $72(34 \%)$ & \\
\hline \multicolumn{4}{|l|}{ Surgical procedure } \\
\hline Lobectomy & $15(58 \%)$ & $133(62 \%)$ & \multirow[t]{3}{*}{0.05} \\
\hline Segmentectomy & $3(12 \%)$ & $53(25 \%)$ & \\
\hline Wedge resection & $8(31 \%)$ & $28(13 \%)$ & \\
\hline
\end{tabular}

SCC, squamous cell carcinoma; ADC, adenocarcinoma; COPD, chronic obstructive pulmonary disease; IP, interstitial; CPFE, combined pulmonary fibrosis and emphysema.

Table II. Pathological characteristics of patients with SCC and all ADC.

\begin{tabular}{lccc}
\hline Variables & $\begin{array}{c}\text { SCC } \\
(\mathrm{n}=26)\end{array}$ & $\begin{array}{c}\text { ADC } \\
(\mathrm{n}=214)\end{array}$ & P-value \\
\hline $\begin{array}{l}\text { Mean tumor } \\
\text { size } \pm \text { SD (mm) }\end{array}$ & $1.59 \pm 0.36$ & $1.43 \pm 0.39$ & 0.05 \\
Pleural invasion & & & \\
$\quad$ Negative & $16(67 \%)$ & $185(87 \%)$ & $<0.01$ \\
Positive & $8(33 \%)$ & $27(13 \%)$ & \\
Vascular invasion & & & \\
$\quad$ Negative & $12(50 \%)$ & $179(85 \%)$ & $<0.01$ \\
Positive & $12(50 \%)$ & $32(15 \%)$ & \\
Lymphatic invasion & & & $<0.01$ \\
$\quad$ Negative & $12(50 \%)$ & $171(81 \%)$ & \\
Positive & $12(50 \%)$ & $40(19 \%)$ & \\
\hline
\end{tabular}

SCC, squamous cell carcinoma; ADC, adenocarcinoma; SD, standard deviation.

identified as a poor-prognosis factor, even in stage IA non-small cell lung cancer, because of a higher rate of distant metastasis (21-23). Lymphatic invasion was also related to a poor prognosis in stage IA non-small cell lung cancer $(24,25)$, and several studies found that lymphatic invasion was correlated
Table III. Postoperative recurrence and survival rates of patients with SCC and all ADC.

\begin{tabular}{lccc}
\hline Variables & $\begin{array}{c}\text { SCC } \\
(\mathrm{n}=26)\end{array}$ & $\begin{array}{c}\text { ADC } \\
(\mathrm{n}=214)\end{array}$ & P-value \\
\hline $\begin{array}{l}\text { Median follow-up period } \\
\text { (months) }\end{array}$ & 38.5 & 58.0 & \\
Recurrence & & & \\
Absent & $20(77 \%)$ & $193(90 \%)$ & 0.04 \\
Present & $6(23 \%)$ & $21(10 \%)$ & \\
Pattern of recurrence & & & 0.08 \\
Locoregional & 2 & 15 & \\
$\begin{array}{l}\text { Distant } \\
\text { Both simultaneously }\end{array}$ & 3 & 3 & \\
\hline SCC, squamous cell carcinoma; ADC, adenocarcinoma. & \\
\hline
\end{tabular}

with a higher rate of lymph node metastasis (26). The association between small-sized peripheral SCC and these malignant factors may contribute to its higher postoperative recurrence rate.

Several reports have shown a favorable prognosis for ADC with GGN component compared with solid ADC $(27,28)$. Similarly, our results showed worse malignant potential of solid ADC compared with ADC with GGN component. The 
Table IV. Pathological characteristics of patients with SCC and two groups of patients with ADC.

\begin{tabular}{|c|c|c|c|c|c|}
\hline Variables & $\operatorname{SCC}(n=26)(\%)$ & $\operatorname{sADC}(n=61)(\%)$ & $\operatorname{nsADC}(\mathrm{n}=153)(\%)$ & P-value ${ }^{\dagger}$ & P-value \\
\hline \multicolumn{6}{|c|}{ Pleural invasion } \\
\hline Negative & $16(67)$ & $42(69)$ & $143(95)$ & $<0.01$ & $<0.01$ \\
\hline Positive & $8(33)$ & $19(31)$ & $8(5)$ & & \\
\hline \multicolumn{6}{|c|}{ Vascular invasion } \\
\hline Negative & $12(50)$ & $35(58)$ & $144(95)$ & $<0.01$ & $<0.01$ \\
\hline Positive & $12(50)$ & $25(42)$ & $7(5)$ & & \\
\hline \multicolumn{6}{|c|}{ Lymphatic invasion } \\
\hline Negative & $12(50)$ & $34(57)$ & $137(91)$ & $<0.01$ & $<0.01$ \\
\hline Positive & $12(50)$ & $26(43)$ & $14(9)$ & & \\
\hline
\end{tabular}

${ }^{\dagger} \mathrm{P}$-value comparing the SCC group with the nsADC group; ${ }^{\star} \mathrm{P}-\mathrm{v}$ alue comparing the sADC group with the nsADC group. SCC, squamous cell carcinoma; sADC, solid adenocarcinoma; nsADC, non-solid adenocarcinoma.

Table V. Postoperative recurrence and survival rates of patients with SCC and two groups of patients with ADC.

\begin{tabular}{|c|c|c|c|c|c|}
\hline Variables & $\operatorname{SCC}(n=26)$ & $\mathrm{sADC}(\mathrm{n}=61)$ & nsADC $(n=153)$ & P-value ${ }^{\dagger}$ & P-value ${ }^{\ddagger}$ \\
\hline Median follow-up period (months) & 38.5 & 56.2 & 59.6 & & \\
\hline \multicolumn{6}{|l|}{ Surgical procedure } \\
\hline Lobectomy & $15(58 \%)$ & $46(75 \%)$ & $87(57 \%)$ & 0.06 & 0.06 \\
\hline Segmentectomy & $3(12 \%)$ & $9(15 \%)$ & $44(29 \%)$ & & \\
\hline Wedge resection & $8(31 \%)$ & $6(10 \%)$ & $22(14 \%)$ & & \\
\hline \multicolumn{6}{|l|}{ Recurrence } \\
\hline Absent & $20(77 \%)$ & $47(77 \%)$ & $146(95 \%)$ & $<0.01$ & $<0.01$ \\
\hline Present & $6(23 \%)$ & $14(23 \%)$ & $7(5 \%)$ & & \\
\hline \multicolumn{6}{|l|}{ Pattern of recurrence } \\
\hline Locoregional & 2 & 10 & 5 & 0.47 & 1.00 \\
\hline Distant & 3 & 2 & 1 & & \\
\hline Both simultaneously & 1 & 2 & 1 & & \\
\hline
\end{tabular}

${ }^{\dagger} \mathrm{P}$-value comparing the SCC group with the nsADC group; ${ }^{\circ} \mathrm{P}-\mathrm{v}$ alue comparing the sADC group with the nsADC group. SCC, squamous cell carcinoma; sADC, solid adenocarcinoma; nsADC, non-solid adenocarcinoma.

incidences of pleural invasion, vascular invasion, lymphatic invasion, and postoperative recurrence of the SCC were similar with solid ADC. Therefore, small peripheral tumors can be divided into two groups; solid tumor and non-solid tumor, in terms of malignant potential. Although wedge resection was lower in SADC group compared to SCC, the recurrence rate was almost same. This data may reflect the higher malignant potential of sADC, i.e., ADC with micropapillary pattern which is a well-known malignant factor $(29,30)$.

Previous studies demonstrated that sublobar resection was a potentially valid surgical option for small-sized tumors $(3,4)$, while the results of large-scale multi-institutional prospective randomized trials are awaited to confirm this (e.g., JCOG0802 and CALGB140503). Furthermore, ADCs with a high proportion of ground glass opacity are classified as minimally invasive or non-invasive ADC (ADC in situ) (31), and complete resection of such minimally invasive or non-invasive ADCs leads to an extremely favorable prognosis $(32,33)$. ADC has thus been regarded as a good candidate for sublobar resection, and large-scale multi-institutional prospective randomized trials are currently exploring this issue (e.g., JCOG0804). In contrast, the present study showed that even small-sized SCCs and SADC in the peripheral lung had malignant potential such as higher incidence of pleural, vascular, and lymphatic invasion, suggesting that solid tumors may not be a good candidate for sublobar resection. Further prospective randomized trials are awaited.

The present study had several limitations. First, this study was conducted retrospectively in a single institute and the sample size was too small to obtain a definitive conclusion. Second, we included patients who underwent wedge resection. Although the proportion of wedge resection was higher in the SCC cohort, there was no difference in the rate of local recurrence. Third, we did not perform analysis regarding lymph node metastasis, because our study included cases of wedge resection and segmentectomy with no mediastinal lymph node dissection. Fourth, since our aim in this study was focused on 
SCC, we just divided ADC into the current two categories. There might be further clinicopathological difference between part-solid GGN and pure GGN (28).

In summary, pleural invasion, vascular invasion, and lymphatic invasion are more common in patients with SCC compared with ADC, while SCC is also associated with a higher postoperative recurrence rate. In addition, incidence of these factors in SCC are similar with SADC. SCC and sADC may not be candidates for sublobar resection even if they are small-sized and located in the peripheral lung.

\section{Acknowledgements}

Not applicable.

\section{Funding}

No funding was received.

\section{Availability of data and materials}

All data and materials in the present study were anonymized. All data generated or analyzed during this study are included in this published article.

\section{Authors' contributions}

TK and KiS conceived and designed the study. SN, MI, YO, YA, KO, TN, AM, HK, KeS and TY obtained the data. TK, KiS and SN analyzed and interpreted the data. TK, KiS, SN and YO drafted the manuscript. MI, YA, KO, TN, TY, AM, $\mathrm{HK}$ and $\mathrm{KeS}$ critically revised the manuscript. All authors have read and approved the manuscript.

\section{Ethics approval and consent to participate}

The present study was approved by the Institutional Review Board of Gunma University Hospital (Maebashi, China) (approval no. 2017-027). Written informed consent was obtained from all patients prior to enrolment.

\section{Patient consent for publication}

All patients consented for their data and/or images to be published at the time of their surgeries.

\section{Competing interests}

The authors declare that they have no competing interests.

\section{References}

1. Port JL, Kent MS, Korst RJ, Libby D, Pasmantier M and Altorki NK: Tumor size predicts survival within stage IA non-small cell lung cancer. Chest 124: 1828-1833, 2003.

2. Okada M, Nishio W, Sakamoto T, Uchino K, Yuki T, Nakagawa A and Tsubota N: Effect of tumor size on prognosis in patients with non-small cell lung cancer: The role of segmentectomy as a type of lesser resection. J Thorac Cardiovasc Surg 129: 87-93, 2005.

3. Koike T, Koike T, Sato S, Hashimoto T, Aoki T, Yoshiya K, Yamato Y, Watanabe T, Akazawa K, Toyabe SI, et al: Lobectomy and limited resection in small-sized peripheral non-small cell lung cancer. J Thorac Dis 8: 3265-3274, 2016.
4. Okada M, Koike T, Higashiyama M, Yamato Y, Kodama K and Tsubota N: Radical sublobar resection for small-sized non-small cell lung cancer: A multicenter study. J Thorac Cardiovasc Surg 132: 769-775, 2006.

5. Huhti E, Saloheimo M, Sutinen S and Reinilä A: Does the location of lung cancer affect its prognosis? Eur J Respir Dis 64: 460-465, 1983 .

6. Tomashefski JF Jr, Connors AF Jr, Rosenthal ES and Hsiue IL: Peripheral vs. central squamous cell carcinoma of the lung. A comparison of clinical features, histopathology, and survival. Arch Pathol Lab Med 114: 468-474, 1990.

7. Krimsky W, Muganlinskaya N, Sarkar S, Vulchi M, Patel P, Rao S, Hammer J, Evans R, Qureshi M and Harley D: The changing anatomic position of squamous cell carcinoma of the lung-a new conundrum. J Community Hosp Intern Med Perspect 6: 33299, 2016.

8. Funai K, Yokose T, Ishii G, Araki K, Yoshida J, Nishimura M, Nagai K, Nishiwaki Y and Ochiai A: Clinicopathologic characteristics of peripheral squamous cell carcinoma of the lung. Am J Surg Pathol 27: 978-984, 2003.

9. Hayashi T, Sano H, Egashira R, Tabata K, Tanaka T, Nakayama T, Kashima Y, Hori T, Nunomura S and Fukuoka J: Difference of morphology and immunophenotype between central and peripheral squamous cell carcinomas of the lung. Biomed Res Int 2013: 157838, 2013.

10. Sakurai H, Asamura H, Watanabe S, Suzuki K and Tsuchiya R: Clinicopathologic features of peripheral squamous cell carcinoma of the lung. Ann Thorac Surg 78: 222-227, 2004.

11. Fukui T, Katayama T, Ito L, Abe T, Hatooka S and Mitsudomi T: Clinicopathological features of small-sized non-small cell lung cancer with mediastinal lymph node metastasis. Lung Cancer 66: 309-313, 2009.

12. Nagashima T, Sakao Y, Mun M, Ishikawa Y, Nakagawa K, Masuda M and Okumura S: A clinicopathological study of resected small-sized squamous cell carcinomas of the peripheral lung: Prognostic significance of serum carcinoembryonic antigen levels. Ann Thorac Cardiovasc Surg 19: 351-357, 2013.

13. Maeshima AM, Maeshima A, Asamura $\mathrm{H}$ and Matsuno $\mathrm{Y}$ : Histologic prognostic factors for small-sized squamous cell carcinomas of the peripheral lung. Lung Cancer 52: 53-58, 2006.

14. Kinoshita T, Ohtsuka T, Hato T, Goto T, Kamiyama I, Tajima A, Emoto K, Hayashi Y and Kohno M: Prognostic factors based on clinicopathological data among the patients with resected peripheral squamous cell carcinomas of the lung. J Thorac Oncol 9: 1779-1787, 2014

15. Tao H, Hayashi T, Sano F, Takahagi A, Tanaka T, Matsuda E and Okabe K: Prognostic impact of lymphovascular invasion compared with that of visceral pleural invasion in patients with pNO non-small-cell lung cancer and a tumor diameter of $2 \mathrm{~cm}$ or smaller. J Surg Res 185: 250-254, 2013.

16. Inoue M, Minami M, Shiono H, Sawabata N, Ideguchi K and Okumura M: Clinicopathologic study of resected, peripheral, small-sized, non-small cell lung cancer tumors of $2 \mathrm{~cm}$ or less in diameter: Pleural invasion and increase of serum carcinoembryonic antigen level as predictors of nodal involvement. J Thorac Cardiovasc Surg 131: 988-993, 2006.

17. Shimizu K, Yoshida J, Nagai K, Nishimura M, Ishii G, Morishita Y and Nishiwaki Y: Visceral pleural invasion is an invasive and aggressive indicator of non-small cell lung cancer. J Thorac Cardiovasc Surg 130: 160-165, 2005.

18. Yoshida J, Nagai K, Asamura H, Goya T, Koshiishi Y, Sohara Y, Eguchi K, Mori M, Nakanishi Y, Tsuchiya R, et al: Visceral pleura invasion impact on non-small cell lung cancer patient survival: Its implications for the forthcoming TNM staging based on a large-scale nation-wide database. J Thorac Oncol 4: 959-963, 2009.

19. Kawase A, Yoshida J, Miyaoka E, Asamura H, Fujii Y, Nakanishi Y, Eguchi K, Mori M, Sawabata N, Okumura M, et al: Visceral pleural invasion classification in non-small-cell lung cancer in the 7th edition of the tumor, node, metastasis classification for lung cancer: Validation analysis based on a large-scale nationwide database. J Thorac Oncol 8: 606-611, 2013.

20. Manac'h D, Riquet M, Medioni J, Le Pimpec-Barthes F, Dujon A and Danel C: Visceral pleura invasion by non-small cell lung cancer: An underrated bad prognostic factor. Ann Thorac Surg 71: 1088-1093, 2001.

21. Tsuchiya T, Akamine S, Muraoka M, Kamohara R, Tsuji K, Urabe S, Honda S and Yamasaki N: Stage IA non-small cell lung cancer: Vessel invasion is a poor prognostic factor and a new target of adjuvant chemotherapy. Lung Cancer 56: 341-348, 2007. 
22. Shoji F, Haro A, Yoshida T, Ito K, Morodomi Y, Yano T and Maehara Y: Prognostic significance of intratumoral blood vessel invasion in pathologic stage IA non-small cell lung cancer. Ann Thorac Surg 89: 864-869, 2010.

23. Shimada Y, Saji H, Yoshida K, Kakihana M, Honda H,Nomura M, Usuda J, Kajiwara N, Ohira T and Ikeda N: Pathological vascular invasion and tumor differentiation predict cancer recurrence in stage IA non-small-cell lung cancer after complete surgical resection. J Thorac Oncol 7: 1263-1270, 2012.

24. Harada M, Hato T and Horio H: Intratumoral lymphatic vessel involvement is an invasive indicator of completely resected pathologic stage I non-small cell lung cancer. J Thorac Oncol 6: $48-54,2011$.

25. Funai K, Sugimura H, Morita T, Shundo Y, Shimizu K and Shiiya N: Lymphatic vessel invasion is a significant prognostic indicator in stage IA lung adenocarcinoma. Ann Surg Oncol 18: 2968-2972, 2011.

26. Kang DY and Lee S: Lymphatic vessel invasion and lymph node metastasis in patients with clinical stage I non-small cell lung cancer. Thorac Cardiovasc Surg 62: 521-524, 2014.

27. Asamura H, Hishida T, Suzuki K, Koike T, Nakamura K, Kusumoto M, Nagai K, Tada H, Mitsudomi T, Tsuboi M, et al: Radiographically determined noninvasive adenocarcinoma of the lung: Survival outcomes of Japan Clinical Oncology Group 0201. J Thorac Cardiovasc Surg 146: 24-30, 2013.

28. Suzuki K, Kusumoto M, Watanabe S, Tsuchiya R and Asamura H: Radiologic classification of small adenocarcinoma of the lung: Radiologic-pathologic correlation and its prognostic impact. Ann Thorac Surg 81: 413-419, 2006.
29. Miyoshi T, Satoh Y, Okumura S, Nakagawa K, Shirakusa T, Tsuchiya E and Ishikawa Y: Early-stage lung adenocarcinomas with a micropapillary pattern, a distinct pathologic marker for a significantly poor prognosis. Am J Surg Pathol 27: 101-109, 2003.

30. Kamiya K, Hayashi Y, Douguchi J, Hashiguchi A, Yamada T, Izumi Y, Watanabe M, Kawamura M, Horinouchi $\mathrm{H}$, Shimada N, et al: Histopathological features and prognostic significance of the micropapillary pattern in lung adenocarcinoma. Mod Pathol 21: 992-1001, 2008.

31. Travis WD, Brambilla E, Nicholson AG, Yatabe Y, Austin JHM, Beasley MB, Chirieac LR, Dacic S, Duhig E, Flieder DB, et al: The 2015 world health organization classification of lung tumors: Impact of genetic, clinical and radiologic advances since the 2004 classification. J Thorac Oncol 10: 1243-1260, 2015.

32. Yoshida J, Nagai K, Yokose T, Nishimura M, Kakinuma R, Ohmatsu $\mathrm{H}$ and Nishiwaki Y: Limited resection trial for pulmonary ground-glass opacity nodules: Fifty-case experience. J Thorac Cardiovasc Surg 129: 991-996, 2005.

33. Maeshima AM, Tochigi N, Yoshida A, Asamura H, Tsuta K and Tsuda H: Histological scoring for small lung adenocarcinomas $2 \mathrm{~cm}$ or less in diameter: A reliable prognostic indicator. J Thorac Oncol 5: 333-339, 2010. 